\title{
Antiretroviral Therapeutic Drug Monitoring in Canada: Current Status and Recommendations for Clinical Practice
}

\author{
Niamh Higgins, Alice Tseng, Nancy L Sheehan, and Charles J L la Porte
}

\section{INTRODUCTION}

$\mathrm{T}$ herapeutic drug monitoring (TDM) is a strategy whereby the plasma concentration of one or more drugs is measured and drug doses are adjusted accordingly to achieve concentrations within an acceptable therapeutic range. The goal of TDM is to maximize pharmacologic efficacy and minimize the drug's toxic effects, and hence to contribute to optimizing the patient's outcomes.

In general, TDM is indicated if the following conditions are present: there is a direct relationship between drug exposure and pharmacologic response, the drug has a narrow therapeutic index and is used to treat a condition for which drug failure or toxicity is associated with substantial morbidity or mortality, and there is limited intrapatient but wide interpatient pharmacokinetic variation. Differences in pharmacokinetic factors among patients are multifactorial and may include age, sex, ethnic background, pregnancy, and body weight, as well as comorbid conditions causing variations in hepatic function, renal function, drug absorption, and drug disposition. In some cases, genetic polymorphisms in the cytochrome P450 enzymes may explain the large interpatient variability for certain antiretroviral agents. For example, certain CYP2B6 and CYP2A6 polymorphisms are independent predictors of plasma concentrations of efavirenz. ${ }^{1}$ Moreover, the potential for complex or unpredictable drug-drug or drug-food interactions can significantly affect plasma drug concentrations. ${ }^{2,3}$ Finally, TDM depends on the availability of an accurate and feasible analytical method for a given drug.

Among antiretroviral agents, the protease inhibitors and the non-nucleoside reverse transcriptase inhibitors (NNRTIs) are considered suitable candidates for TDM. ${ }^{4-6}$ Evidence exists of a relation between exposure to antiretrovirals and virologic response and, in more limited instances, between exposure to the drug and toxic effects. ${ }^{5,6}$ Recent data have suggested that intraindividual variation is limited $(19.0 \%$ for NNRTIs and $38.1 \%$ for protease inhibitors). 7 Preliminary data have also suggested that trough levels of maraviroc, a chemokine $(\mathrm{C}-\mathrm{C}$ motif) receptor 5 (CCR5) antagonist, are predictive of virologic outcome, ${ }^{8}$ although TDM experience with this agent is extremely limited. In retrospective ${ }^{9}$ and prospective ${ }^{10,11}$ studies, observed interindividual variability in drug concentrations has been $45 \%$ to $112 \%$ for protease inhibitors and $75 \%$ for NNRTIs. Thus, a given dose of a particular antiretroviral agent may result in unacceptable toxic effects in some patients while yielding subtherapeutic concentrations in others. TDM represents a tool by which the effectiveness of these agents in clinical practice can be optimized through dosage adjustments tailored to patient-specific pharmacokinetic and pharmacodynamic parameters.

The current article reviews the literature on antiretroviral TDM, describes the development of an antiretroviral TDM program in Canada, and illustrates the role of the pharmacist in the clinical application of TDM. Given current evidence and personal experience, the authors support the use of antiretroviral TDM as a clinical tool in special patient populations and for specific clinical situations.

\section{PROSPECTIVE STUDIES EVALUATING ANTIRETROVIRAL TDM}

Prospective randomized trials have confirmed the utility of TDM in attaining virologic end points consistent with treatment efficacy and/or decreasing the incidence of toxic effects in treatment-naive subjects (i.e., patients who are receiving their first antiretroviral regimen). In the AIDS Therapy Evaluation in the Netherlands (ATHENA) study, patients initiating either indinavir- or nelfinavir-based regimens were randomly assigned to receive either TDM or usual care. ${ }^{12}$ At 48 weeks of followup, a significantly higher proportion of patients in the TDM 
group had achieved HIV RNA levels below 500 copies $/ \mathrm{mL}$ relative to control patients $(78.2 \%$ versus $55.1 \%, p=0.003)$. Similarly, in a separate study, antiretroviral-naive patients initiating therapy with zidovudine, lamivudine, and indinavir were randomly assigned to receive either concentration-controlled therapy or standard-dose therapy. ${ }^{13}$ Significantly more patients in the concentration-controlled group than in the standarddose group achieved the target drug concentrations, and 15 (94\%) of 16 patients in the concentration-controlled group but only $9(53 \%)$ of 17 patients in the standard-dose group attained plasma HIV RNA levels below 50 copies $/ \mathrm{mL}$ over 52 weeks of therapy $(p=0.017)$.

These studies had limitations. First, they included only patients who were naive to antiretroviral drugs at the time of enrolment, which prevents extrapolation of results to patients with more extensive antiretroviral experience and viral resistance. Furthermore, patients in these studies took protease inhibitor drugs that are given without ritonavir boosting and that are no longer used as first-line therapy (i.e., indinavir and nelfinavir). Therefore, these results are not necessarily applicable to protease inhibitors taken with ritonavir or to NNRTIs.

Plasma concentrations of various antiretrovirals have been correlated with specific toxic effects in several retrospective studies; in particular, indinavir with nephrolithiasis, ${ }^{14}$ efavirenz with toxic effects in the central nervous system (CNS), ${ }^{15}$ nevirapine with hepatotoxicity, ${ }^{16}$ atazanavir with hyperbilirubinemia, ${ }^{17-20}$ and lopinavir with dyslipidemia. ${ }^{21}$ A study of 151 TDM requests for 137 patients revealed clinical benefit of TDM in identifying and correcting toxic levels of NNRTIs and subtherapeutic levels of protease inhibitors. Dose adjustments for antiretrovirals led to resolution of drug-related toxic effects or improvement in virologic response rates in a substantial portion of these patients. ${ }^{22}$

In patients with protease inhibitor experience, drug resistance is related to the accumulation of mutations, and higher concentrations of the drug may be required to suppress drug-resistant virus. It may be possible to overcome resistance in a particular patient by achieving higher plasma concentrations. The inhibitory quotient (IQ) is the ratio of trough concentration of antiretroviral to a measure of resistance. Measures of either phenotypic resistance (concentration needed to inhibit $50 \%$ or $90 \%$ of the virus $\left[\mathrm{IC}_{50}\right.$ or $\left.\mathrm{IC}_{90}\right]$ ) or genotypic resistance (number of protease inhibitor-associated resistance mutations) are used in the IQ calculations, resulting in phenotypic IQ (PIQ) or genotypic IQ (GIQ), respectively. IQ values have been shown to independently predict virologic response to protease inhibitor therapy in treatment-experienced populations, ${ }^{6,23}$ and proposed cutoff IQ values are now available. In one retrospective study, the authors concluded that virologic response was more closely related to target GIQ than to the target minimum concentration $\left(C_{\mathrm{min}}\right)$ for protease inhibitor-experienced patients; also, GIQ-based TDM interpretations tended to improve virologic response, provided the treating physicians followed the pharmacologic advice. ${ }^{24} \mathrm{~A}$ clinical application of the GIQ will be described later, and more information on these parameters can be found in the literature. $^{25}$

The results of 4 randomized controlled trials (namely, the PharmAdapt, ${ }^{26}$ GENOPHAR, ${ }^{27}$ RADAR [Resistance and Dosage Adapted Regimens $],{ }^{27}$ and POPIN ${ }^{10}$ studies) did not support the routine use of TDM for all patients receiving antiretroviral therapy. Overall, these studies demonstrated no differences in virologic and immunologic outcomes between the patients who received antiretroviral TDM and those who received usual care. However, these studies had several limitations, which may explain why TDM had no significant benefit. In the POPIN study, more than two-thirds of the patients had virologic suppression at baseline, which would have made it difficult to detect significant differences in virologic failure between the groups. ${ }^{10}$ In the PharmAdapt and GENOPHAR studies the target concentrations selected might not have been adequate for patients with multidrug-resistant viruses. $^{26,27}$ Furthermore, at 4 weeks, the duration of the PharmAdapt study was probably too short to demonstrate any benefit of TDM. ${ }^{26}$ Another major shortcoming of these studies was poor adherence (as low as 30\%) with pharmacologic advice by the treating physician. ${ }^{28}$ Other factors that may have contributed to the lack of benefit of TDM in these studies include delayed implementation of TDM recommendations, inclusion of patients with highly treatment-resistant virus, and lack of statistical power.

Given the results and limitations of the aforementioned studies, antiretroviral TDM appears best suited for specific patient populations and clinical scenarios. In pediatrics, drug absorption, metabolism, and clearance are 3 age-dependent parameters that may change substantially as organ systems evolve through normal maturation. Hepatic impairment secondary to cirrhosis, viral hepatitis infection, and/or antiretroviral hepatotoxicity may cause substantial decreases in the amount and function of the CYP enzymes, which are the main route of metabolism for protease inhibitors and NNRTIs. Pregnancy is associated with physiologic changes such as decreased gastric motility, increased total body water and fat stores, altered plasma protein concentrations, and increased activity of the hepatic enzymes, all of which may affect drug disposition. ${ }^{29}$ Concentrations of the protease inhibitors have been shown to be lower in the second and third trimesters of pregnancy than before pregnancy and after delivery. ${ }^{30}$ TDM can also help to identify and guide management in situations in which the patient is at risk of complex, unpredictable, and clinically significant drug interactions that may result in increased toxic effects or compromised drug efficacy. Other potential 
indications for TDM include routine measurements for protease inhibitors that are given without ritonavir boosting, once-daily protease inhibitors for which there is a risk of suboptimal $C_{\min }$ at the end of the 24-h dosing interval (e.g., fosamprenavir and saquinavir), and recent virological failure.

Current HIV treatment guidelines, including those developed by the British HIV Association ${ }^{31}$ and the US Department of Health and Human Services, ${ }^{4}$ incorporate these principles and endorse the use of TDM in selected situations, such as treatment failure, pregnancy, pediatrics, dosage adjustment in the context of organ dysfunction, suspected toxicity, and monitoring of clinically significant drug-drug interactions that might compromise antiretroviral effectiveness. These indications are summarized in Table $1 . .^{4,31-34}$ In addition, a variety of antiretroviral TDM programs and services already exist both in Canada (in the province of Quebec) and internationally (in the Netherlands, the United Kingdom, the United States, Italy, France, Germany, and other European countries). In France and the Netherlands, TDM has been incorporated as a routine standard of care for many years. A brief summary of existing programs appears in Online Appendix 1 (see supplementary data for this article at www.cjhp-online.ca/pages/files/ Vol62No6HigginsAppendix.pdf).

\section{ANTIRETROVIRAL TDM IN CANADA}

Numerous laboratories in Canada (e.g., Ottawa, Toronto, Vancouver, and Montréal) have developed the analytical methods to quantify antiretroviral agents and are now measuring these medications for research purposes. At present, only the Quebec Antiretroviral Therapeutic Drug Monitoring Program offers such a service as usual care for the clinical management of people living with HIV. This section provides an overview of the steps in developing and implementing an antiretroviral TDM program, focusing on the Quebec experience as an example.

In 2002, HIV clinicians in Quebec requested a provincial antiretroviral TDM program on the basis of the known pharmacokinetic and pharmacodynamic relationships for these drugs, prospective studies in antiretroviral-naive patients, and the growing clinical experience from European sites. A consortium of HIV clinicians (general practitioners, specialists, and pharmacists), the Comité consultatif sur la prise en charge clinique des personnes vivant avec le VIH (Consulting Committee on the Clinical Care of People Living with HIV), wrote an extensive report justifying the need for antiretroviral TDM. The consortium presented its report to the provincial health ministry, the Ministère de la Santé et des Services Sociaux du Québec (MSSS), with a funding request for a centralized antiretroviral TDM program that would serve all medical clinics and hospitals in the province. Although the ministry readily accepted the principle of antiretroviral TDM, it took 3 years for the necessary funding to be obtained and a laboratory chosen on the basis of a lengthy tender process. In 2005, the McGill University Health Centre (MUHC) secured the Quebec Antiretroviral Therapeutic Drug Monitoring Program. The MSSS mandated the Biochemistry Department of the Royal Victoria Hospital (affiliated with MUHC) to develop the analytical method to measure protease inhibitors and NNRTIs. The analytical method that was developed involves liquid chromatography coupled with tandem mass spectrometry. The pharmacists of the Pharmacy Department and Immunodeficiency Service of the Montreal Chest Institute (also affiliated with MUHC) underwent specialized training in antiretroviral TDM and then developed and implemented a service for interpreting the plasma concentrations of antiretrovirals.

Once the development of an antiretroviral TDM program had been approved and the funding confirmed, the following steps were required to develop and implement the service:

- Develop the analytical method and regularly participate in internal and external quality control tests for validation.

- Determine the indications for antiretroviral TDM.

- Determine the clinical data needed for accurate interpretation of plasma concentrations and construct a data collection form (see Online Appendix 2, in the supplementary data for this article, at www.cjhp-online.ca/pages/files/ Vol62No6HigginsAppendix.pdf).

- Establish the procedure and instructions for procuring, handling, storing, and transporting samples.

- $\quad$ Select target values for the pharmacokinetic parameters (see Table $2^{12,14,15,27,35-51}$ ) and the method of interpretation on the basis of an extensive literature review.

- Coordinate workflow interactions between clinics, external laboratories, the main laboratory for the antiretroviral TDM program, and the interpretation service.

- Create a database and a method for reporting results back to the referring physicians.

- Organize and provide continuing education sessions on antiretroviral TDM for physicians, pharmacists, nurses, patients, biochemists, administrators, and others as appropriate.

After consultation with experts in the field, biochemist colleagues, HIV physicians and pharmacologists, pharmacists, patients and the community at large, and MSSS representatives, the Quebec Antiretroviral Therapeutic Drug Monitoring Program was established. Implementation of such a program is lengthy and expensive. The one-time costs related to the purchase of laboratory equipment for the Quebec program were about $\$ 500000$, and the annual costs for running the program average $\$ 350000$.

The workflow within the program is as follows. When a physician or clinical pharmacist identifies an indication for 
Table 1. Indications for Antiretroviral Therapeutic Drug Monitoring in Various HIV Treatment Guidelines*

\begin{tabular}{lccccc} 
Indication or Population & $\begin{array}{c}\text { BHIVA } \\
\text { 2008 }\end{array}$ & $\begin{array}{c}\text { EACS } \\
\mathbf{2 0 0 8}\end{array}$ & $\begin{array}{c}\text { Germany-Austria } \\
\mathbf{2 0 0 4}\end{array}$ & $\begin{array}{c}\text { France } \\
\mathbf{2 0 0 6}\end{array}$ & $\begin{array}{c}\text { DHHS } \\
\mathbf{2 0 0 8}\end{array}$ \\
\hline Treatment failure & $\mathrm{B}$ & $\mathrm{C}$ & $\mathrm{B}$ & $\mathrm{B}$ & $\mathrm{C}$ \\
Interactions & $\mathrm{B}$ & & $\mathrm{B}$ & $\mathrm{B}$ & $\mathrm{C}$ \\
Liver impairment & $\mathrm{B}$ & & $\mathrm{B}$ & $\mathrm{B}$ & $\mathrm{C}$ \\
Children & $\mathrm{B}$ & & & $\mathrm{B}$ & \\
Pregnant women & $\mathrm{B}$ & & $\mathrm{B}$ & $\mathrm{C}$ \\
Malabsorption & $\mathrm{B}$ & $\mathrm{B}$ & & $\mathrm{C}$ \\
Once-daily dosing & $\mathrm{B}$ & & & $\mathrm{C}$ \\
Toxicity & & & $\mathrm{B}$ & & $\mathrm{C}$
\end{tabular}

Adherence concerns

B

BHIVA = British HIV Association ${ }^{31}$ EACS $=$ European AIDS Clinical Society, ${ }^{32}$ Germany-Austria = German-Austrian recommendations for antiretroviral therapy of HIV infection, ${ }^{33}$ France $=$ French Experts Group's Recommendations for Medical Management of HIV Infection, ${ }^{34} \mathrm{DHHS}=$ US Department of Health and Human Services, ${ }^{4} \mathrm{~B}=$ monitoring recommended, $\mathrm{C}=$ monitoring should be considered.

*Adapted with permission from Dr S Khoo, University of Liverpool.

Table 2. Targets for Minimum Concentration and Genotypic Inhibitory Quotient for Antiretroviral Agents

\begin{tabular}{|c|c|c|c|c|}
\hline \multirow[b]{2}{*}{ Antiretroviral Agent } & \multicolumn{2}{|c|}{$C_{\min }(\mathrm{mg} / \mathrm{L})$} & \multicolumn{2}{|r|}{ GIQ } \\
\hline & PI-naive Patients & $\begin{array}{c}\text { Patients with History } \\
\text { of PI Failure }\end{array}$ & $\begin{array}{c}\text { Concentration } \\
\text { (mg/L per mutation) }\end{array}$ & $\begin{array}{c}\text { Viral Mutations } \\
\text { Used in Calculation }\end{array}$ \\
\hline \multicolumn{5}{|l|}{$\begin{array}{l}\text { Non-nucleoside reverse } \\
\text { transcriptase inhibitors }\end{array}$} \\
\hline Efavirenz & $1.0-4.0^{15}$ & NA & NA & NA \\
\hline Nevirapine & $3.0-8.0^{35,36}$ & NA & NA & NA \\
\hline \multicolumn{5}{|l|}{ Protease inhibitors } \\
\hline Amprenavir (fosamprenavir) & $0.4^{37}$ & $1.6^{38}$ & $0.3^{38}$ & $\begin{array}{l}\text { Zephir score } 38 \text { : any of 10, 13V, } \\
\text { 19l/QN, 32I, 33, 36, 46, 47V, } \\
50 \mathrm{~V}, 54,55 \mathrm{R}, 62,63,71,73, \\
82,84,89 \mathrm{M}, 90\end{array}$ \\
\hline Atazanavir ${ }^{39}$ & 0.15 & 0.15 & 0.1 & $\begin{array}{l}\text { IAS-USA 2004*: 10F///RN, 20M/R, } \\
24 \mathrm{I}, 30 \mathrm{~N}, 32 \mathrm{I}, 33 \mathrm{~F}, 36 \mathrm{l}, 46 \mathrm{I} / \mathrm{L}, \\
47 \mathrm{~V} / \mathrm{A}, 48 \mathrm{~V}, 50 \mathrm{~V}, 50 \mathrm{~L}, 53 \mathrm{~L}, \\
\text { 54V/L/AM/T/S, 63P,71V/T, 73S, } \\
\text { 77I, 82A/F/T, 84V, 88D/S, 90M }\end{array}$ \\
\hline Darunavir & NA & $2.2^{40}$ & $>2.15^{41}$ & $\begin{array}{l}\text { IAS-USA 200841: 11I, 32I, 33F, 47V, } \\
\text { 50V, 54L/M, 73S, 76V, 84V, 89V }\end{array}$ \\
\hline Indinavir & $\begin{array}{c}0.1^{42} \\
\left(C_{\max } 10^{14}\right)\end{array}$ & $0.75^{43}$ & NA & NA \\
\hline Lopinavir & $1.0^{44}$ & $5.0^{45}$ & $2.1^{46}$ & $\begin{array}{l}\text { Isaacson score }{ }^{46,47}: 10,20,24,33, \\
36,47,48,54,82,84\end{array}$ \\
\hline Nelfinavir & $0.8^{12}$ & NA & NA & NA \\
\hline Saquinavir & $0.1^{48,49}$ & $0.1^{27}$ & $>0.35^{50}$ & $\begin{array}{l}\text { IAS-USA 200550: 10I/RN, 48V, } \\
54 \mathrm{~V} / \mathrm{L}, 71 \mathrm{~V} / \mathrm{T}, 73 \mathrm{~S}, 77 \mathrm{I}, 82 \mathrm{~A}, 84 \mathrm{~V}\end{array}$ \\
\hline Tipranavir & NA & $20.5^{51}$ & $14.5^{51}$ & $\begin{array}{l}\text { Valdez score }{ }^{51}: 10 \mathrm{~V}, 13 \mathrm{~V}, 20 \mathrm{M} / \mathrm{RN}, \\
\text { 33F, 35G, 36I, 43T, 46L, 47V, } \\
\text { 54AMMN, 58E, 69K, 74P,82L/, } \\
\text { 83D, 84V }\end{array}$ \\
\hline
\end{tabular}

$\mathrm{C}_{\max }=$ maximum concentration, $\mathrm{C}_{\min }=$ minimum concentration, $\mathrm{GlQ}$ = genotypic inhibitory quotient,

IAS-USA = International AIDS Society_USA, NA = not applicable, PI = protease inhibitor.

* Gonzalez de Requena and others ${ }^{41}$ based their analysis on the 2004 mutation list of the IAS-USA with additional mutations. 
antiretroviral TDM, a data collection form is completed (see Online Appendix 2, in the supplementary data for this article, at www.cjhp-online.ca/pages/files/Vol62No6HigginsAppendix.pdf) and a blood sample (one 5-mL heparin tube, green top) is obtained from the patient, ideally at the end of the dosing interval. To ensure appropriate isolation of the plasma, staff in the biochemistry laboratory centrifuge the samples (at $3000 \mathrm{~g}$ for $5 \mathrm{~min}$ ) within $6 \mathrm{~h}$ of collection. A 1-mL sample of plasma in a cryotube is sufficient to measure multiple antiretrovirals. The completed data collection form and plasma sample are then sent to the central TDM program laboratory. If the sample is shipped the same day as procurement, it can be refrigerated until shipment and sent at room temperature. If the sample is sent on a different day, it should be stored at below $-20^{\circ} \mathrm{C}$. Samples for which transport is expected to exceed $48 \mathrm{~h}$ should be placed in a shipment box with dry ice. Once the sample arrives at the TDM program laboratory, the plasma concentration of the drug or drugs is measured, and the results are sent to the program's interpretation service, where the TDM pharmacist interprets the data. An interpretation report with pharmacologic advice is written and mailed to the referring physician. The average turnaround time for measurement and interpretation is 2 weeks (i.e., from the time the sample is received at the laboratory to mailing of the interpretation report).

The Quebec Antiretroviral Therapeutic Drug Monitoring Program began offering services to all patients with HIV in the province of Quebec in June 2006. On average, 1400 antiretroviral samples are measured annually. The most common indications for antiretroviral TDM are control (39.1\%), toxic effects, (17.3\%), drug interactions (16.3\%), and virologic failure (16.0\%). The antiretroviral drugs most commonly measured are atazanavir (31.7\%), lopinavir (26.6\%), and efavirenz (19.9\%). The Biochemistry Department regularly validates the analytical method both internally and externally. For example, every 2 years the laboratory participates in the International Interlaboratory Quality Control Program for Measurement of Antiretroviral Drugs in Plasma. ${ }^{52}$ Quality assurance studies on the interpretation service have also been performed, including a survey of physicians, which indicated that overall, physicians were satisfied with the program..$^{53}$ Program pharmacists also conduct retrospective and prospective pharmacokinetic and pharmacodynamic studies and deliver regular continuing education sessions on antiretroviral TDM. As of 2009, the services of the Quebec Antiretroviral Therapeutic Drug Monitoring Program are offered to sites across Canada that wish to outsource this analysis. A blood sample requiring measurement of one protease inhibitor or NNRTI costs $\$ 60$, which includes the interpretation report. For every additional drug that is measured in a given sample (excluding ritonavir), the charge is $\$ 40$. For example, TDM for a patient taking lopinavir, ritonavir, and saquinavir would cost $\$ 100$.
Separate interpretation reports would be provided for lopinavir and saquinavir, with no results provided for ritonavir (because this drug is used only for pharmacokinetic boosting, rather than as a therapeutic antiretroviral drug). Shipping costs are the responsibility of the requesting site.

For pharmacists desiring to develop a similar program, 5 key tips should be kept in mind:

- Ensure that funding has been secured, and obtain written confirmation of support from the sponsor before starting to develop the program.

- Seek advice from and specialized training with experts in antiretroviral TDM.

- Obtain support and collaboration from treating physicians and biochemists.

- Review the scientific literature frequently, as antiretroviral TDM remains a dynamic field, with rapid changes in interpretation methods and targets.

- Consider outsourcing antiretroviral TDM requests if the disadvantages of developing an in-house service outweigh the benefits.

\section{ROLE OF THE PHARMACIST IN TDM}

To help readers to achieve a better understanding of the role of pharmacists in antiretroviral TDM, this section presents an overview of the practical organization of TDM and a discussion of the roles of the various health care professionals who are involved.

At the HIV clinic, the clinical pharmacist communicates with the treating physician and the patient in any case in which TDM is desired. The clinical pharmacist organizes the TDM request and communicates with the TDM provider. The TDM provider should provide clear instructions about handling the sample and the background clinical information that will be needed for analysis and interpretation. Once the drug in the sample has been measured, the clinical pharmacist can use the advice provided by the TDM pharmacist to improve the patient's pharmaceutical care plan. The physician, in collaboration with the clinical pharmacist, makes the final decision on adjusting the antiretroviral dose, on the basis of the interpretation report and further clinical data (e.g., the patient's willingness to change therapy, adverse drug reactions, pill burden). Any dose adjustment should be followed by repeat analysis to confirm the effect of the intervention.

At the site of the TDM service, the TDM pharmacist is responsible for organizing the drug measurements, interpreting the results, and communicating with the requestor. At some sites the TDM pharmacist may be the same person as the clinical pharmacist, depending on the organization. The TDM pharmacist will use the clinical information and the laboratory results to develop meaningful advice to be reported back to the requestor. 
The TDM pharmacist must keep pace with the continuous growth of HIV knowledge, as well as the specifics of HIV-related TDM. Each individual TDM pharmacist must take responsibility for staying up to date, as no programs for training and accreditation are yet in place.

In general, the TDM pharmacist needs the following information for appropriate interpretation of the laboratory results:

- reliable laboratory results (with the laboratory ideally being enrolled in both internal and external quality control programs)

- clear identification of the patient and complete contact information for the requestor

- patient's basic clinical information such as height, weight, age, sex, pregnancy status, changes in kidney and liver function, resistance data, viral load, and CD4 cell count

- patient's current antiretroviral therapy, including dosages and frequency of administration

- patient's other pharmaceutical treatments, including overthe-counter and natural health products

- indication for TDM request

- list of $\operatorname{drug}(s)$ to be monitored

- date and time of the last dose of the drug that is to be monitored

- date and time of blood sampling

- information about whether the medication was taken with or without food

All of this information is usually obtained by the treating physician, clinic nurse, or pharmacist at the time of sample procurement (see Online Appendix 2, in the supplementary data for this article, at www.cjhp-online.ca/pages/files/ Vol62No6HigginsAppendix.pdf).

Table 2 presents a list of the concentration-based cutoff values currently used by Quebec TDM pharmacists for interpretation of laboratory results. ${ }^{12,14,15,27,35-51}$ These cutoff values are based on trough or $C_{\min }$ samples. For monitoring efficacy, the ideal would be to analyze a trough level (about $12 \mathrm{~h}$ after dosing for twice-daily intake or $24 \mathrm{~h}$ after dosing for once-daily intake). Alternatively, if the sample was not taken at the end of the dosing interval, the concentration of the drug can be compared with a $C_{\min }$ curve constructed using the target $C_{\min }$ and the pharmacokinetic curve of the given antiretroviral. The $C_{\min }$ can also be extrapolated using the mean population halflife for the specific drug. The choice of one method over the other is mainly at the discretion of the TDM pharmacist, depending on preference and experience.

For treatment-experienced patients who may have drugresistant virus, information about the sensitivity of the virus is also important. The TDM pharmacist can combine drug concentrations and phenotypic or genotypic resistance information using the IQ. This approach allows target plasma concentrations to be individualized as a function of the degree of viral resistance acquired. Because phenotypes are not routinely available in Canada, the GIQ is most often used. Table 2 summarizes the current cutoff values for GIQ-based TDM.

When TDM is used for monitoring toxic effects, it should be kept in mind that clear cutoff values for these effects have been defined for only a limited number of drugs. In practice, when toxicity is present, TDM will be used mainly to determine if the levels are high enough in terms of efficacy to allow the dose to be reduced. If TDM is used in this way, trough levels are logically the most helpful.

When unexpected values for drug concentrations are encountered, it is important for the clinic pharmacist to recognize the results as unexpected and to handle them appropriately to prevent incorrect conclusions. The clinic pharmacist, in consultation with the TDM pharmacist, must rule out other factors such as incorrect dose or dosing frequency, disregard of food requirements, interactions with other drugs in the regimen, absence of steady-state conditions, sampling or laboratory error, or complete, partial, or sporadic nonadherence.

TDM can be an advantageous clinical tool, but it is helpful only when combined with other equally important treatment considerations. TDM results may lead to changes in the patient's drug regimen, in terms of dosages of existing drugs or initiation of new drugs. Therefore, an understanding of drug interactions, resistance mutations, and the management of toxic effects is very important if the patient is to fully benefit from TDM. In reality, any adjustments based on TDM results should be conducted in consultation with an expert clinical or TDM pharmacist, the treating physician, and (where necessary and available) an expert clinical virologist.

\section{Summary of Recommended Indications for Antiretroviral TDM}

TDM of antiretrovirals may be most useful when employed for the following indications.

Special patient populations:

- $\quad$ pregnant patients

- $\quad$ pediatric patients

- geriatric patients

- patients with hepatic impairment

- $\quad$ patients with obesity or cachexia

Clinical scenarios:

- drug-drug interactions

- $\quad$ side effects of certain antiretroviral drugs

- $\quad$ suspected malabsorption

- virologic failure

- unconventional antiretroviral dosing

- once-daily dosing of certain protease inhibitors (e.g., fosamprenavir, saquinavir) 


\section{CLINICAL SCENARIOS}

Two clinical scenarios (based on the types of cases that the authors typically see in their TDM practice) are presented here to demonstrate how antiretroviral TDM may be applied in clinical practice.

\section{Case 1: Toxicity of the Antiretroviral Regimen}

HIV was diagnosed in a 56-year-old man in May 2008. At the time of diagnosis, the HIV RNA viral load was 150000 copies $/ \mathrm{mL}$, and the CD 4 count was 214 cells $/ \mu \mathrm{L}$. The patient's initial antiretroviral regimen consisted of efavirenz $600 \mathrm{mg}$ once daily at bedtime and tenofovir-emtricitabine $300 \mathrm{mg}-200 \mathrm{mg}$ one tablet once daily.

Two weeks later, the patient presented to the immunodeficiency clinic reporting CNS symptoms, including dizziness, somnolence, and nightmares. The clinic pharmacist assured the patient that these side effects were common during the first month of therapy and that in most cases the symptoms dissipate over time.

Five weeks later, the patient returned to the clinic with persistent CNS symptoms. The pharmacist suggested measuring the plasma concentration of efavirenz. The concentration was $5.77 \mathrm{mg} / \mathrm{L}$ at $14 \mathrm{~h}$ after dosing. The pharmacist interpreted this concentration as toxic, given the well-defined therapeutic range for efavirenz between 1 and $4 \mathrm{mg} / \mathrm{L}^{15,54,55}$ (Figure 1). In the figure, the minimum and maximum target thresholds for efavirenz are depicted as straight lines because of the nature of the drug's pharmacokinetic profile (a very long elimination half-life, ranging from 40 to $\left.55 \mathrm{~h}^{56}\right)$. Given the patient's unresolved CNS symptoms and the supratherapeutic drug concentration, the pharmacist suggested a dose decrease, from $600 \mathrm{mg}$ to $400 \mathrm{mg}$. Notably, the results of laboratory testing at the time of TDM indicated that the patient had achieved an undetectable viral load (less than 50 copies $/ \mathrm{mL}$ ) and immunologic response (CD4 count 230 cells $/ \mu \mathrm{L}$ ).

Three weeks later, the patient returned to the clinic reporting a dramatic improvement in his CNS symptoms. The pharmacist suggested repeat TDM for efavirenz to confirm that the plasma levels of efavirenz were therapeutic, despite belowconventional dosing. The efavirenz concentration was 3.23 $\mathrm{mg} / \mathrm{L}$ at $13 \mathrm{~h}$ after dosing, a therapeutic result (see Figure 1). Of note, because of the long elimination half-life of this drug and bedtime dosing, concentrations are usually measured between 10 and $14 \mathrm{~h}$ after dosing instead of $24 \mathrm{~h}$ after dosing. In addition, the patient's viral load remained undetectable (i.e., $<50$ copies $/ \mathrm{mL}$ ), and his CD4 count was 255 cells $/ \mu \mathrm{L}$.

\section{Case 2: Multidrug-Resistant Virus and Calculation of a GIQ}

A 44-year-old woman had multidrug-resistant HIV. The physician prescribed a regimen of lopinavir-ritonavir $400 \mathrm{mg}-$
$100 \mathrm{mg}$ twice daily, tenofovir $300 \mathrm{mg}$ once daily, and abacavir-lamivudine $600 \mathrm{mg}-300 \mathrm{mg}$ one tablet once daily. Genotypic data indicated that the virus had moderate resistance to several antiretroviral drugs. The protease gene had a number of mutations (at positions 10, 50, 54, 63, 71, 73, and 90), which conferred resistance to protease inhibitors. Moreover, mutations on the reverse transcriptase gene (at positions 41, 184, and 215) conferred moderate resistance to nucleoside reverse transcriptase inhibitor (NRTI) drugs.

On November 3, 2008, before initiation of the antiretroviral therapy, the patient's HIV RNA was 124200 copies/mL and the CD4+ count was 113 cells/ $\mu \mathrm{L}$. On December 15 , 2008, after 6 weeks of antiretroviral therapy, the patient's HIV RNA had decreased to 95300 copies $/ \mathrm{mL}$ (a 0.12 log decrease), which the physician considered to be suboptimal. The patient reported excellent adherence to her therapy, with no missed doses during the past month. The physician decided to measure the lopinavir concentration. At $10 \mathrm{~h}$ after dosing, the plasma concentration of lopinavir was $4.2 \mathrm{mg} / \mathrm{L}$, below the target $C_{\min }$ curve for this drug for a patient with a history of virologic failure or resistance (Figure 2). ${ }^{57,58} \mathrm{~A}$ pharmacokinetic population curve was used in this case because the blood sample had not been obtained at $12 \mathrm{~h}$ after dosing. The extrapolated $C_{\min }$ of lopinavir for this patient, based on the mean population half-life of $8.9 \mathrm{~h}$ associated with the laboratory's pharmacokinetic curve for this drug, was $3.6 \mathrm{mg} / \mathrm{L}$. This value was below the target $C_{\min }$ of $5 \mathrm{mg} / \mathrm{L}$ for patients with a history of failure of protease inhibitor therapy. ${ }^{37}$

Using data from the patient's cumulative resistance tests, the TDM pharmacist compiled a list of all protease mutations expressed by the patient's virus: at positions 10, 50, 54, 63, 71, 73 , and 90 . The lopinavir GIQ was calculated using mutations from the Isaacson mutation score, ${ }^{47}$ which includes mutations known to be associated with decreased virologic response to lopinavir (mutations at positions 10, 20, 24, 33, 36, 47, 48, 54, 82, and 84). Therefore, this patient's viral species had 2 lopinavir-associated mutations from the Isaacson mutation score, namely, at positions 10 and 54 .

The GIQ was calculated as follows:

GIQ for lopinavir $=C_{\min } /$ no. of lopinavir-associated mutations from Isaacson mutation score

$=3.6 \mathrm{mg} / \mathrm{L} \div 2$ mutations

$=1.8 \mathrm{mg} / \mathrm{L}$ per mutation

The target GIQ value for lopinavir associated with an increased likelihood of virologic response is $2.1 \mathrm{mg} / \mathrm{L}$ per mutation. ${ }^{46}$ The result for this patient was therefore subtherapeutic on the basis of both the extrapolated $C_{\min }$ of lopinavir and the lopinavir GIQ.

The TDM pharmacist suggested that the physician and clinical pharmacist verify and encourage the patient's adherence with therapy. However, because the patient's adherence was already judged to be optimal, the TDM pharmacist also suggested that the lopinavir-ritonavir dosage be increased to 


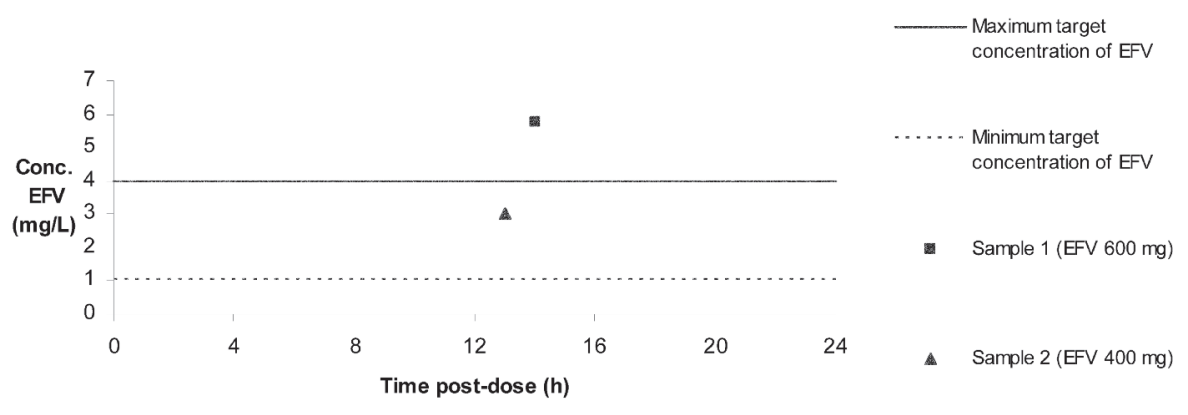

Figure 1. Case 1. Plasma concentrations of efavirenz (EFV) in a patient with central nervous system symptoms. Solid horizontal line $=$ maximum target threshold; dashed horizontal line $=$ minimum target threshold.

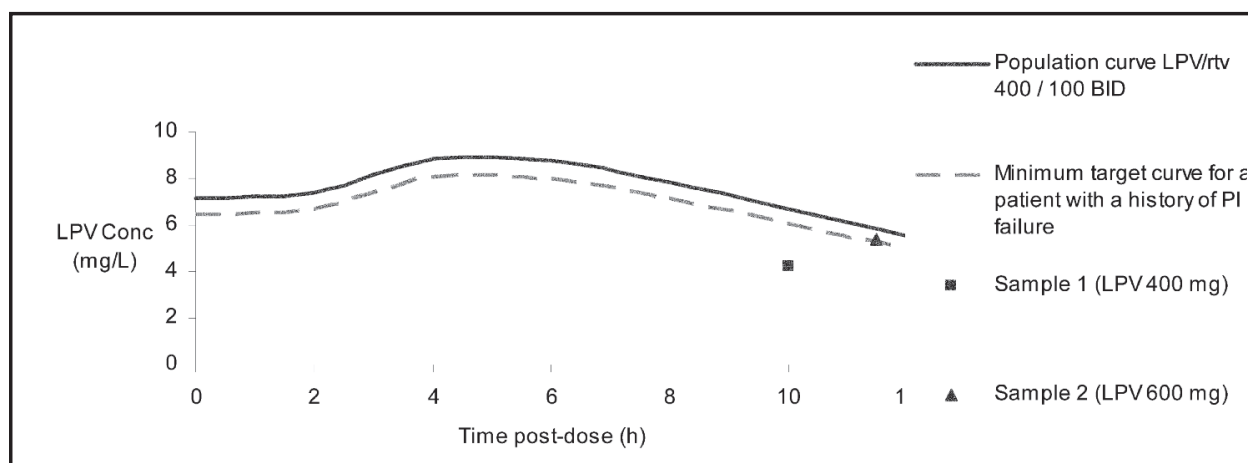

Figure 2. Case 2. Plasma concentrations of lopinavir (LPV) in a patient with virological failure. Solid line = population curve for lopinavir, for patients receiving lopinavir-ritonavir $400 \mathrm{mg}-100 \mathrm{mg}$ twice daily; dashed line $=$ minimum target curve for a patient with a history of failure of protease inhibitor therapy.

$600 \mathrm{mg}-150 \mathrm{mg}$ bid in an attempt to reach the target GIQ. In addition, the TDM pharmacist suggested repeat TDM of lopinavir 1 week after the dose adjustment to ensure that the new dose was leading to therapeutic lopinavir levels.

On January 5, 2009, the TDM pharmacist received a new lopinavir result for this patient: $5.4 \mathrm{mg} / \mathrm{L}$ at $11.5 \mathrm{~h}$ after dosing, reflecting the dose increase for lopinavir-ritonavir. The extrapolated $C_{\min }$ for lopinavir was estimated at $5.2 \mathrm{mg} / \mathrm{L}$ and the GIQ was $2.6 \mathrm{mg} / \mathrm{L}$ per mutation, indicating a therapeutic result. In addition, the HIV RNA obtained on January 5 (about 3 weeks after the dose increase) was 18222 copies $/ \mathrm{mL}$, denoting a $0.83 \log$ decrease from baseline and indicating a good response to therapy.

\section{CONCLUSIONS}

TDM is used to optimize the effectiveness of antiretroviral drugs and, in some instances, to alleviate their adverse effects, through dosage adjustments tailored to patient-specific pharmacokinetic and pharmacodynamic parameters. The GIQ incorporates resistance data and drug concentrations and thus may have a higher predictive capacity for virologic response than drug concentrations alone. The current body of literature suggests that TDM is most valuable when used in certain patient populations and in specific clinical situations. TDM is most beneficial when used as part of an integrated approach to overall clinical management. The Quebec experience demonstrates that developing and implementing a centralized antiretroviral TDM service is a lengthy process with numerous considerations. Pharmacists practising in HIV care settings can have an active role in TDM and can use pharmacokinetic data to improve overall pharmaceutical care. The authors recommend that antiretroviral TDM be offered routinely to people living with HIV because of its clinical utility for specific indications.

\section{References}

1. Kwara A, Lartey M, Sagoe KW, Rzek NL, Court MH. CYP2B6 (c.516 G-->T) and CYP2A6 ( ${ }^{*} 9 \mathrm{~B}$ and/or $\left.{ }^{*} 17\right)$ polymorphisms are independent predictors of efavirenz plasma concentrations in HIV-infected patients. $\mathrm{Br}$ J Clin Pharmacol 2009;67(4):427-436.

2. Ensom MH, Davis GA, Cropp CD, Ensom RJ. Clinical pharmacokinetics in the 21st century. Does the evidence support definitive outcomes? Clin Pharmacokinet 1998;34(4):265-279. 
3. Spector R, Park GD, Johnson GF, Vesell ES. Therapeutic drug monitoring. Clin Pharmacol Ther 1988;43(4):345-353.

4. Panel on Antiretroviral Guidelines for Adult and Adolescents. Guidelines for the use of antiretroviral agents in HIV-1-infected adults and adolescents. Rockville (MD): Department of Health and Human Services; 2008 [cited 2009 Jan 11]. Available from: http://www.aidsinfo.nih.gov/ ContentFiles/AdultandAdolescentGL.pdf

5. Back D, Gibbons S, Khoo S. An update on therapeutic drug monitoring for antiretroviral drugs. Ther Drug Monit 2006;28(3):468-473.

6. La Porte CJL, Back DJ, Blaschke T, Boucher CAB, Fletcher CV, Flexner $\mathrm{C}$, et al. Updated guidelines to perform therapeutic drug monitoring for antiretroviral agents. Rev Antiviral Ther 2006;3:4-14.

7. Fabbiani M, Di Giambenedetto S, Bracciale L, Bacarelli A, Ragazzoni E, Cauda R, et al. Pharmacokinetic variability of antiretroviral drugs and correlation with virological outcome: 2 years of experience in routine clinical practice. J Antimicrob Chemother 2009;64(1):109-117.

8. McFayden L, Jacqmin P, Wade J, Weatherley B. Maraviroc exposure response analysis: phase 3 antiviral efficacy in treatment-experienced HIV+ patients. In: 16th meeting of the PAGE Population Approach Group in Europe; 2007 Jun 13-15; Kobenhavn, Denmark.

9. Guiard-Schmid JB, Poirier JM, Meynard JL, Bonnard P, Gbadoe AH, Amiel C, et al. High variability of plasma drug concentrations in dual protease inhibitor regimens. Antimicrob Agents Chemother 2003; 47(3):986-990.

10. Khoo SH, Lloyd J, Dalton M, Bonington A, Hart E, Gibbons S, et al. Pharmacologic optimization of protease inhibitors and nonnucleoside reverse transcriptase inhibitors (POPIN) - a randomized controlled trial of therapeutic drug monitoring and adherence support. J Acquir Immune Defic Syndr 2006;41(4):461-467.

11. Molto J, Blanco A, Miranda C, Miranda J, Puig J, Valle M, et al. Variability in non-nucleoside reverse transcriptase and protease inhibitors concentrations among HIV-infected adults in routine clinical practice. Br J Clin Pharmacol 2007;63(6):715-721.

12. Burger D, Hugen P, Reiss P, Gyssens I, Schneider M, Kroon F, et al. Therapeutic drug monitoring of nelfinavir and indinavir in treatmentnaive HIV-1-infected individuals. AIDS 2003;17(8):1157-1165.

13. Fletcher CV, Anderson PL, Kakuda TN, Schacker TW, Henry K, Gross $\mathrm{CR}$, et al. Concentration-controlled compared with conventional antiretroviral therapy for HIV infection. AIDS 2002;16(4):551-560.

14. Dieleman JP, Gyssens IC, van der Ende ME, de Marie S, Burger DM. Urological complaints in relation to indinavir plasma concentrations in HIV-infected patients. AIDS 1999;13(4):473-478.

15. Marzolini C, Telenti A, Decosterd LA, Greub G, Biollaz J, Buclin T. Efavirenz plasma levels can predict treatment failure and central nervous system side effects in HIV-1-infected patients. AIDS 2001;15(1):71-75.

16. Gonzalez de Requena D, Nunez M, Jimenez-Nacher I, Soriano V. Liver toxicity caused by nevirapine. AIDS 2002;16(2):290-291.

17. Cleijsen RM, van de Ende ME, Kroon FP, Lunel FV, Koopmans PP, Gras L, et al. Therapeutic drug monitoring of the HIV protease inhibitor atazanavir in clinical practice. J Antimicrob Chemother 2007;60(4):897-900.

18. Gonzalez de Requena D, Bonora S, Cavechia I, Marrone R, D’Avolio A, Sciandra M. Atazanavir $C_{\text {trough }}$ is associated with efficacy and safety at 24 weeks: definition of therapeutic range. In: 6th International Workshop on Clinical Pharmacology of HIV Therapy; 2005 Apr 28-30; Québec (QC).

19. Molto J, Santos JR, Valle M, Miranda C, Miranda J, Blanco A, et al. Monitoring atazanavir concentrations with boosted or unboosted regimens in HIV-infected patients in routine clinical practice. Ther Drug Monit 2007;29(5):648-651.

20. Ray JE, Marriott D, Bloch MT, McLachlan AJ. Therapeutic drug monitoring of atazanavir: surveillance of pharmacotherapy in the clinic. Br J Clin Pharmacol 2005;60(3):291-299.
21. Gutierrez F, Padilla S, Navarro A, Masia M, Hernandez I. Lipid abnormalities in HIV-infected patients and lopinavir plasma concentrations. J Acquir Immune Defic Syndr 2004;36(5):1107-1109.

22. Rendon A, Nunez M, Jimenez-Nacher I, Gonzalez de Requena D, Gonzalez-Lahoz J, Soriano V. Clinical benefit of interventions driven by therapeutic drug monitoring. HIV Med 2005;6(5):360-365.

23. Winston A, Khoo S. Clinical application of the inhibitory quotient: is there a role in HIV protease inhibitor therapy? Curr Opin HIV AIDS 2008;3(6):608-611.

24. Sheehan NL, Higgins NM, Boulerice A, Lalonde R. Evaluation of the use of genotypic inhibitory quotients in an antiretroviral therapeutic drug monitoring program. In: 8th International Workshop on Clinical Pharmacology of HIV Therapy; 2007 Apr 16-18; Budapest, Hungary.

25. La Porte C. Inhibitory quotient in HIV pharmacology. Curr Opin HIV AIDS 2008;3(3):283-287.

26. Clevenbergh P, Garraffo R, Durant J, Dellamonica P. PharmAdapt: a randomized prospective study to evaluate the benefit of therapeutic monitoring of protease inhibitors: 12 week results. AIDS 2002; 16(17):2311-2315.

27. Bossi P, Peytavin G, Ait-Mohand H, Delaugerre C, Ktorza N, Paris L, et al. GENOPHAR: a randomized study of plasma drug measurements in association with genotypic resistance testing and expert advice to optimize therapy in patients failing antiretroviral therapy. HIV Med 2004;5(5): 352-359.

28. Torti C, Quiros-Roldan E, Regazzi M, De Luca A, Mazzotta F, Antinori A, et al. A randomized controlled trial to evaluate antiretroviral salvage therapy guided by rules-based or phenotype-driven HIV-1 genotypic drug-resistance interpretation with or without concentration-controlled intervention: the Resistance and Dosage Adapted Regimens (RADAR) study. Clin Infect Dis 2005;40(12):1828-1836.

29. Loebstein R, Koren G. Clinical relevance of therapeutic drug monitoring during pregnancy. Ther Drug Monit 2002;24(1):15-22.

30. Mirochnick M, Capparelli E. Pharmacokinetics of antiretrovirals in pregnant women. Clin Pharmacokinet 2004;43(15):1071-1087.

31. Gazzard BG. British HIV Association guidelines for the treatment of HIV-1-infected adults with antiretroviral therapy 2008. HIV Med 2008;9(8):563-608.

32. Clumeck N, Pozniak A, Raffi F. European AIDS Clinical Society (EACS) guidelines for the clinical management and treatment of HIV-infected adults. HIV Med 2008;9(2):65-71.

33. Salzberger B, Marcus U, Vielhaber B, Arasteh K, Golz J, Brockmeyer NH, et al. German-Austrian recommendations for the antiretroviral therapy of HIV-infection (status May 2004). Eur J Med Res 2004;9(11):491-504.

34. Yeni P, Aronica E, Blanche S, Bourliere M, Brun-Vezinet F, Chemlal K, et al. French Experts Group's recommendations for medical management of HIV infection. Paris (France): Ministère de la Santé; 2006 [cited 2009 Oct 28]. Available from: http://www.sante.gouv.fr/htm/actu/yeni_sida/ rapport_experts_angl_2006.pdf

35. de Vries-Sluijs TE, Dieleman JP, Arts D, Huitema AD, Beijnen JH, Schutten $\mathrm{M}$, et al. Low nevirapine plasma concentrations predict virological failure in an unselected HIV-1-infected population. Clin Pharmacokinet 2003;42(6):599-605.

36. Duong M, Buisson M, Peytavin G, Kohli E, Piroth L, Martha B, et al. Low trough plasma concentrations of nevirapine associated with virologic rebounds in HIV-infected patients who switched from protease inhibitors. Ann Pharmacother 2005;39(4):603-609.

37. Sadler BM, Gillotin C, Lou Y, Stein DS. Pharmacokinetic and pharmacodynamic study of the human immunodeficiency virus protease inhibitor amprenavir after multiple oral dosing. Antimicrob Agents Chemother 2001;45(1):30-37.

38. Pellegrin I, Breilh D, Coureau G, Boucher S, Neau D, Merel P, et al. Interpretation of genotype and pharmacokinetics for resistance to fosamprenavir-ritonavir-based regimens in antiretroviral-experienced patients. Antimicrob Agents Chemother 2007;51(4):1473-1480. 
39. Gonzalez de Requena D, Bonora S, Canta F, Marrone R, D’Avolio A, Sciandra M. Atazanavir trough is associated with efficacy and safety: definition of therapeutic range. In: 12th Conference on Retroviruses and Opportunistic Infections; 2005 Feb 22-25; Boston (MA).

40. Sekar V, Abeele CV, Van Baelen B, Vis P, Lavreys L, De Pauw M. Pharmacokinetic/pharmacodynamic analyses of once-daily darunavir in the ARTEMIS study. In: 15th Conference on Retroviruses and Opportunistic Infections: 2008 Feb 3-6; Boston (MA).

41. Gonzalez de Requena D, Calcagno A. Effect of darunavir (DRV) genotypic inhibitory quotient (gIQ) on the virological response to DRVcontaining salvage regimens at 24 weeks In: 9th International Workshop on Clinical Pharmacology of HIV Therapy: 2008 Apr 7-9; New Orleans (LA).

42. Burger DM, van Rossum AM, Hugen PW, Suur MH, Hartwig NG, Geelen SP, et al. Pharmacokinetics of the protease inhibitor indinavir in human immunodeficiency virus type 1 -infected children. Antimicrob Agents Chemother 2001;45(3):701-705.

43. Shulman N, Zolopa A, Havlir D, Hsu A, Renz C, Boller S, et al. Virtual inhibitory quotient predicts response to ritonavir boosting of indinavir-based therapy in human immunodeficiency virus-infected patients with ongoing viremia. Antimicrob Agents Chemother 2002; 46(12):3907-3916.

44. Ananworanich J, Kosalaraksa P, Hill A, Siangphoe U, Bergshoeff A, Pancharoen C, et al. Pharmacokinetics and 24-week efficacy/safety of dual boosted saquinavir/lopinavir/ritonavir in nucleoside-pretreated children. Pediatr Infect Dis J 2005;24(10):874-879.

45. González de Requena D, García-Benayas T, Gallego O, Blanco F, Valer L, Jimenez-Nacher I. Predictive power of genotypic inhibitory quotient and lopinavir plasma levels in both efficacy and lipid elevations of LPV/r-based salvage regimens at 48 weeks. In: 11 th Conference on Retroviruses and Opportunistic Infections; 2004 Feb 8-11; San Francisco (CA).

46. Marcelin AG, Cohen-Codar I, King MS, Colson P, Guillevic E, Descamps $\mathrm{D}$, et al. Virological and pharmacological parameters predicting the response to lopinavir-ritonavir in heavily protease inhibitor-experienced patients. Antimicrob Agents Chemother 2005;49(5):1720-1726.

47. Kempf DJ, Isaacson JD, King MS, Brun SC, Sylte J, Richards B, et al. Analysis of the virological response with respect to baseline viral phenotype and genotype in protease inhibitor-experienced HIV-1infected patients receiving lopinavir/ritonavir therapy. Antivir Ther 2002; 7(3):165-174.

48. Fletcher CV, Jiang H, Brundage RC, Acosta EP, Haubrich R, Katzenstein $\mathrm{D}$, et al. Sex-based differences in saquinavir pharmacology and virologic response in AIDS Clinical Trials Group Study 359. J Infect Dis 2004; 189(7):1176-1184.

49. Marcelin AG, Dalban C, Peytavin G, Lamotte C, Agher R, Delaugerre C, et al. Clinically relevant interpretation of genotype and relationship to plasma drug concentrations for resistance to saquinavir-ritonavir in human immunodeficiency virus type 1 protease inhibitor-experienced patients. Antimicrob Agents Chemother 2004;48(12):4687-4692.

50. Lam S, Delisle M, Labbé L, Smith GHR, la Porte CJL, Burger DM, et al. Genotypic inhibitory quotient as best pharmacokinetic/pharmacodynamic predictor of virologic response to a lopinavir/saquinavir dual ritonavirboosted regimen in patients with multiresistant HIV-1. In: 7th International Workshop on Clinical Pharmacology of HIV Therapy; 2006 Apr 20-22; Lisbon, Portugal.

51. Bonora S, Gonzalez de Requena D, Calcagno A, Milia MG, D'Avolio A, Sciandra M. Tipranavir (TPV) genotypic inhibitory quotient (gIQ) predicts early virological response to TPV-based salvage regimens. In: 13th Conference on Retroviruses and Opportunistic Infections; 2006 Feb 5-8; Denver (CO).

52. Aarnoutse RE, Verweij-van Wissen CP, van Ewijk-Beneken Kolmer EW, Wuis EW, Koopmans PP, Hekster YA, et al. International interlaboratory quality control program for measurement of antiretroviral drugs in plasma. Antimicrob Agents Chemother 2002;46(3):884-886.
53. Tang I, Orng B, Benyayer G, Fortier S, Perreault S, Labbé L et al. Evaluation of physician satisfaction with the Québec provincial antiretroviral therapeutic drug monitoring program. In: 9th International Workshop on Clinical Pharmacology of HIV Therapy; 2008 Apr 7-9; New Orleans (LA).

54. Molto J, Valle M, Fumaz CR, Santos J, Clotet B. Evidence of pharmacodynamic tolerance to efavirenz-related neuropsychiatric side effects. In: 8th International Workshop on Clinical Pharmacology of HIV Therapy; 2007; Budapest, Hungary.

55. Nunez M, Gonzalez de Requena D, Gallego L, Jimenez-Nacher I, Gonzalez-Lahoz J, Soriano V. Higher efavirenz plasma levels correlate with development of insomnia. J Acquir Immune Defic Syndr 2001; 28(4):399-400.

56. Sustiva product monograph. Montréal (QC): Bristol-Myers Squibb; 2009.

57. Bertz R, Foit C, Ye X, Manning L, Bernstein B, Renz C. Pharmacokinetics of once-daily vs twice-daily Kaletra (lopinavir/ritonavir) in HIV+ subjects. In: 9th Conference on Retroviruses and Opportunistic Infections; 2002 Feb 24-28; Seattle (WA).

58. Eron JJ, Feinberg J, Kessler HA, Horowitz HW, Witt MD, Carpio FF, et al. Once-daily versus twice-daily lopinavir/ritonavir in antiretroviral-naive HIV-positive patients: a 48-week randomized clinical trial. J Infect Dis 2004;189(2):265-272.

Niamh Higgins, PharmD, AAHIVS, is an HIV Pharmacotherapy Specialist with the Quebec Antiretroviral Therapeutic Drug Monitoring Program and the Immunodeficiency Service, Montreal Chest Institute (McGill University Health Centre), Montréal, Quebec.

Alice Tseng, BSCPhm, PharmD, FSCHP, is an HIV Pharmacotherapy Specialist with the Immunodeficiency Clinic, Toronto General Hospital, Toronto, Ontario.

Nancy L Sheehan, BPharm, MSc, is an Assistant Clinical Professor with the Faculté de pharmacie, Université de Montréal, Montréal, Quebec. She is also an HIV Pharmacotherapy Specialist with the Quebec Antiretroviral Therapeutic Drug Monitoring Program and the Immunodeficiency Service, Montreal Chest Institute (McGill University Health Centre), Montréal, Quebec

Charles J L la Porte, PharmD, PhD, is Pharmacokinetic Director, Clinical Investigation Unit, University of Ottawa, The Ottawa Hospital, and Ottawa Health Research Institute, Ottawa, Ontario.

\section{Address correspondence to:}

Dr Niamh Higgins

Quebec Antiretroviral Therapeutic Drug Monitoring Program Immunodeficiency Service

Montreal Chest Institute (McGill University Health Centre)

3655 St Urbain, D2.01

Montréal QC H2X 2N9

e-mail: niamh.higgins@muhc.mcgill.ca

\section{Acknowledgements}

We acknowledge the contributions of the following individuals: David Burger, Gilles Peytavin, Stefano Bonora, David J Back, and Saye Khoo for providing information about their therapeutic drug monitoring services; and Richard Lalonde, Jean Guy Baril, Ellen Séguin, and Patricia Lefebvre for their involvement in establishing the Quebec Antiretroviral Therapeutic Drug Monitoring Program and for their continued support of the program. In addition, we thank the Ministère de la Santé et des Services Sociaux du Québec for funding the Québec Antiretroviral Therapeutic Drug Monitoring Program. We also thank the members of the Biochemistry Department at the Royal Victoria Hospital (David Blank, Denis Thibeault, David Colantonio, Bernard Grignon, Elyse Levert, Allan Tulli, and Eusebio Ambayec), without whose efforts the program would not exist. 